\title{
Computed tomography-guided platinum microcoil lung surgery: A cross-sectional study
}

Anna L. McGuire, MD, MSc, ${ }^{\mathrm{a}, \mathrm{b}}$ Arthur Vieira, MD, ${ }^{\mathrm{b}}$ Kyle Grant, MD, MSc, ${ }^{\mathrm{b}}$ John Mayo, MD, ${ }^{\mathrm{a}, \mathrm{c}}$

Tony Sedlic, MD, ${ }^{\mathrm{c}}$ James Choi, MD, MPH, ${ }^{\mathrm{b}}$ and John Yee, MD ${ }^{\mathrm{a}, \mathrm{b}}$

\section{ABSTRACT}

Objective: The study objective was to provide a 5-year update on our tertiarylevel institutional experience with computed tomography-guided platinum microcoil lung surgery.

Methods: A retrospective cross-sectional study was conducted. All patients admitted to the Thoracic Service at Vancouver General Hospital to undergo computed tomography-guided microcoil lung surgery were included. Key primary outcome variables were successful nodule localization and severity of adverse events associated with placement. Secondary outcomes included nodule characteristics on preoperative computed tomography chest and nodule surgical pathology. Continuous variables were reported as mean ( \pm standard deviation), and counts were reported as proportions $\mathrm{n}(\%)$.

Results: A total of 97 lung nodules were resected in 92 patients. Mean age was $65.3( \pm 10.6)$ years, and $59(61 \%)$ were female. All 97 nodules $(100 \%)$ were successfully localized using video-assisted thoracic surgery wedge resection. There were 59 cases $(60.8 \%)$ of placement-related events noted on computed tomography of the chest. All were minor and self-limited in nature and did not require treatment: pneumothorax $45(46.4 \%)$, lung hematoma 18 (18.6\%), dislodgement $4(4.1 \%)$, and hemoptysis $2(2.1 \%)$. Mean nodule diameter was $13.2 \mathrm{~mm}( \pm 6.7)$. Density was nonsolid in $27(27.8 \%)$ and semi-solid in $27(27.8 \%)$. There was a single case of positive surgical margin, and $4(4.1 \%)$ went on to completion lobectomy. Non-small lung cancer was identified in 66 nodules.

Conclusions: Computed tomography-guided platinum microcoil lung surgery is safe with a favorable clinical adverse event profile and is suitable for poor-risk patients. The method is efficient, yielding 100\% diagnostic localization in our 5 -year update. It eliminates the need for thoracotomy and palpation to localize worrisome subpleural tiny nodules. It is ideal for the management of changing nodules concerning for early lung cancer and diagnosis of small indeterminate lung nodules or metastases. (J Thorac Cardiovasc Surg 2019;158:594-600)

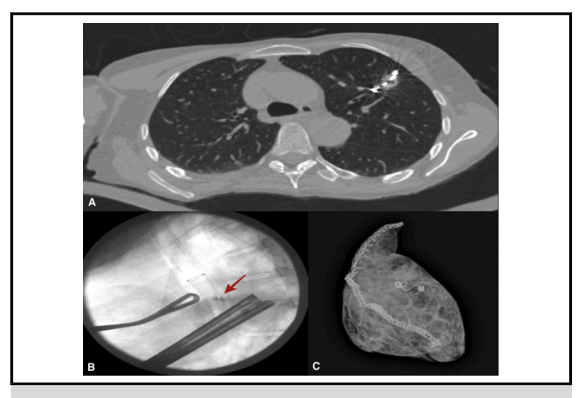

A, CT of the chest showing microcoil placed adjacent to a suspicious nodule. B, Intraoperative microcoil localization (arrom) with fluoroscopy. C, Postresection specimen $\mathrm{x}$-ray showing successful removal of the microcoil marker.

\section{Central Message}

CT-guided microcoil lung surgery is safe with a favorable adverse event profile. It eliminates the need for thoracotomy and palpation to localize worrisome subpleural tiny nodules.

\section{Perspective}

CT-guided microcoil lung surgery is safe with a favorable clinical adverse event profile and is suitable for poor-risk patients. The method is effective and efficient, yielding $100 \%$ diagnostic localization in our 5-year update. It is also ideal for the management of changing nodules concerning for early lung cancer and diagnosis of small indeterminate lung nodules or metastases.

See Commentaries on pages 601 and 603.
Since the landmark National Lung Screen Trial revealed a $20 \%$ improvement in survival with screening computed tomography (CT) of the chest in populations at risk of lung cancer, physicians have been presented with increasing

From the ${ }^{\mathrm{a} V a n c o u v e r}$ Coastal Health Research Institute, Vancouver General Hospital, Vancouver, BC, Canada; ' Department of Surgery, Division of Thoracic Surgery, University of British Columbia, Vancouver, BC, Canada; and ${ }^{\mathrm{c}}$ Department of Diagnostic Medical Imaging, Thoracic Service, University of British Columbia, Vancouver, BC, Canada.

Read at The American Association for Thoracic Surgery Thoracic Summit, New York, New York, October 12-13, 2018.

Received for publication Oct 11, 2018; revisions received March 4, 2019; accepted for publication March 10, 2019; available ahead of print June 10, 2019. numbers of small and nonsolid pulmonary lesions to manage in clinical practice. ${ }^{1}$ Algorithms exist to assess solitary pulmonary nodule malignancy risk in adults, such as the Brock University cancer prediction equation. ${ }^{2}$

\footnotetext{
Address for reprints: Anna L. McGuire, MD, MSc, Division of Thoracic Surgery, Department of Surgery, University of British Columbia, Vancouver Coastal Health Research Institute, Vancouver General Hospital, 7113 - 2775 Laurel St, Vancouver, British Columbia, Canada, V5Z 1M9 (E-mail: anna.mcguire@vch.ca). 0022-5223/\$36.00

Copyright (C) 2019 Published by Elsevier Inc. on behalf of The American Association for Thoracic Surgery https://doi.org/10.1016/j.jtcvs.2019.03.096
} 


\section{Abbreviations and Acronyms}

$$
\begin{array}{ll}
\mathrm{CT} & =\text { computed tomography } \\
\mathrm{ICS} & =\text { intercostal space } \\
\text { LOS } & =\text { length of stay } \\
\text { NSCLC } & =\text { non-small cell lung cancer }
\end{array}
$$

\section{Scanning this QR code will}

take you to the article title page to access supplementary information.

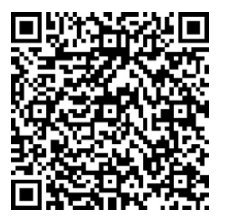

Many lung nodules at high risk for malignancy are not amenable to transthoracic needle biopsy for diagnosis because they are nonsolid or part-solid in density, providing a target too small for success. Excisional biopsy in the form of thoracoscopic wedge resection remains an important tool for diagnosis and possible definitive treatment of these potentially malignant nodules.

The difficulty with thoracoscopic pulmonary wedge resection in the setting of a small or predominantly nonsolid nodule is that there are no visual or tactile clues available to the surgeon to localize the nodule, necessitating adjunct localization techniques. Several different preoperative techniques to assist the surgeon in lung nodule localization have been described. These can be broadly categorized as CT-guided wire localized, CT or bronchoscopy-guided dye or tracer localized, and intraoperative ultrasound guided. ${ }^{3-13}$ Wire-guided techniques involve placement of a microcoil, a spiral coil, or a hook wire with CT-image guidance preoperatively. The main issue with the hook-wire technique is that as the wire passes through the surface of the visceral pleura, associated pneumothorax can dislodge the wire from the nodule as the lung collapses away from the fixed hook in the chest wall. ${ }^{11-13}$ Although dislodgement is less of an issue with spiral wires and subpleural microcoils, this can still occur. ${ }^{14,15}$ Methylene blue, indigo carmine dye, and contrast media injected by needles with CT or bronchoscopic guidance preoperatively have been reported. ${ }^{15-20}$ Blue dyes in general are difficult to contain and can often stain surrounding tissues, limiting precision. Injected radioactive tracer use has been reported with variable success in localization of lung nodules for excision. ${ }^{16-20}$ Intraoperative ultrasound has utility in nodule localization; however, image acquisition can be compromised because the lung must be completely atelectatic for optimal nodule viewing. Complete atelectasis is at times difficult to achieve in emphysematous lungs, a condition seen commonly with patients requiring diagnostic resection of lung nodules to rule out cancer. The CT-guided microcoil technique to mark lung nodules for resection has been reported by our thoracic group in detail in a prospective randomized trial to precisely localize lung nodules for excision with minimal associated morbidity. ${ }^{3}$ This microcoil randomized control trial also demonstrated cost-effectiveness of the procedure.

The objective of the current study is to provide a 5-year update since accrual ended for the microcoil randomized control trial on the clinical, radiologic, and histopathologic outcomes of the microcoil localization in the setting of routine thoracic surgical clinical practice. We hypothesize that microcoil-guided pulmonary surgery for suspected malignant nodules is a safe and efficacious diagnostic and therapeutic tool. The findings of this observational study in routine clinical practice may be more generalizable to other thoracic surgical institutions wanting to adopt the CT-guided microcoil localization technique to excise small or nonsolid lung nodules at high risk for malignancy.

\section{MATERIALS AND METHODS}

\section{Study Design, Setting, and Participants}

After University of British Columbia Human Research Ethics Board approval (\#H18-01472), a single-center, cross-sectional study was conducted for the time period July 1, 2012, to June 30, 2017. Men and women, age 18 years and older, admitted to Vancouver General Hospital and undergoing CT-guided microcoil localized pulmonary surgery were eligible for study inclusion. Eligible participants were identified retrospectively by query of a prospectively maintained thoracic surgical database. Participant medical records were reviewed, including surgical pathology, CT-guided microcoil imaging, and operative reports.

\section{Outcome Variables}

Predefined primary outcomes of interest were 3-fold: (1) complications relating to microcoil placement (pneumothorax, hematoma, hemoptysis, coil dislodgement); (2) cumulative patient radiation exposure during microcoil-guided surgery; and (3) proportion of successful nodule localization. Key secondary outcomes of interest included nodule density on CT of the chest (subsolid, semi-solid, predominantly solid), nodule depth in centimeters from visceral pleura, final surgical pathology, and tumor-free surgical margin in millimeters. The World Health Organization classification of non-small cell lung cancer (NSCLC) and the American Joint Committee on Cancer 8th edition were used for histopathologic reporting of primary pulmonary malignancy.

\section{Statistical Methods}

Analysis was conducted using Stata12 statistical software (version 12, StataCorp LP, College Station, Tex). For descriptive analysis continuous variables were reported as means (standard deviation) and counts as proportions (n, \%). For univariable analysis, categoric variables were examined with chi-square tests and crude odds ratio estimates to assess for association between the primary outcomes and the primary and secondary exposures of interest. Mantel-Haenszel adjusted odds ratio estimates were then conducted to assess the secondary exposures as potential confounding or risk modifying variables. Continuous variables were as mean differences and examined for association with primary outcomes using the Student $t$ test. All statistical tests were 2 tailed. 


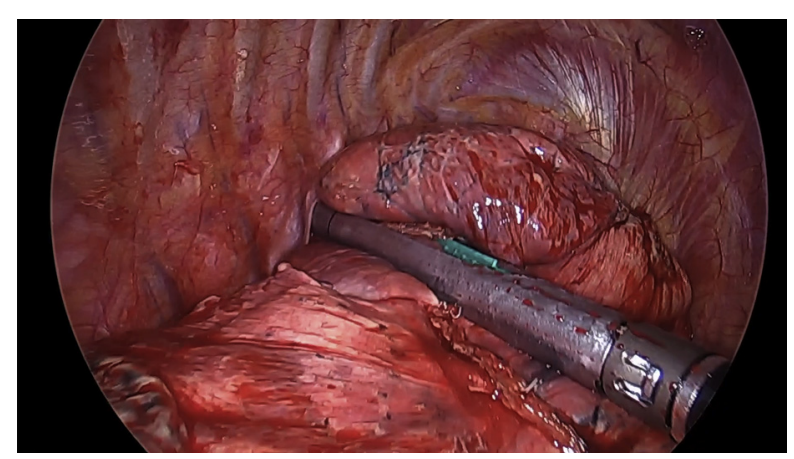

VIDEO 1. The step-by-step process of microcoil-guided lung surgery is shown. With the lung nodule identified on localization CT of the chest, the platinum microcoil within the Chiba needle is placed into the lung parenchyma and ejected. Postplacement CT of the chest assesses final microcoil position relative to the nodule. In the operating room, the lung parenchyma is grasped and microcoil identified using short bursts of fluoroscopy. After the endo-stapler is shown to be clear of the coil at fluoroscopy, it is fired, completing resection. Immediate $\mathrm{x}$-ray of the specimen confirms microcoil removal to assess the margins grossly. We then proceed with systematic sampling of mediastinal and hilar lymph nodes. Video available at: https://www.jtcvs.org/article/S0022-5223(19)30797-4/fulltext.

\section{OPERATIVE TECHNIQUE \\ Microcoil Preparation}

The core of a 150-mm-long Chiba Sugai needle (Cook Canada, Stouffville, Ontario, Canada) is removed (Video 1). The needle has stenciled marks spaced $10 \mathrm{~mm}$ apart on the outside of the needle shaft. An 80-mm-long, 0.018-inch-diameter fiber-coated platinum microcoil (Vortx-18, Diamond Shape; Boston Scientific, Cork, Ireland) is then pushed into the Chiba needle using the stiff end of a 40-cm-long, 0.018-inch-diameter guidewire from a micropuncture catheter introducer set (Mini-Stick Kit; Boston Scientific, Watertown, Mass). After the microcoil is loaded into the needle, using a hemostat, the pusher wire is marked at the length necessary to eject the entire 80-mm-long microcoil from the Chiba needle into the lung. ${ }^{4}$

\section{Microcoil Placement}

With CT guidance, the loaded Chiba needle is pushed through and $5 \mathrm{~mm}$ deep to the suspicious nodule (Figure 1, $A$ ). The premeasured guidewire is then advanced into the Chiba needle up to the level of the hemostat. After this, $30 \mathrm{~mm}$ of the $80-\mathrm{mm}$-long microcoil is deployed into the lung parenchyma (to ensure proper placement). There it assumes a tightly coiled ball-like configuration just beyond the tip of the needle. We then obtain a localizer CT image to confirming microcoil deployment and measure the distance required to withdraw the tip of the Chiba needle back to other side of the nodule. The guidewire is then advanced to the hemostat placed at the mark, where the entire microcoil is ejected into the parenchyma. The microcoil takes the configuration of a flattened spiral coil. The empty needle and guidewire are then withdrawn. A postprocedural CT scan is obtained to assess the final position of the microcoil relative to the nodule. We also assess for presence of postprocedural hemorrhage, as indicated by new airspace consolidation, and pneumothorax. The patient is then transferred to the preoperative area, where they wait 1 to 6 hours before undergoing surgical resection of the nodule. Patients were scheduled for microcoil localization in our radiology department in the morning and for video-assisted thoracic surgery excision later in the day after the major thoracic surgeries for the day are completed. By separating the radiologic and surgical procedural times, we eliminated scheduling conflicts between radiology and surgical departments. ${ }^{4}$

\section{Surgical Procedure}

In the operating room, members of the surgical team are protected using a lead gown and neck protectors. Under general anesthesia, the patient is ventilated with a double-lumen endotracheal tube. In a lateral decubitus position, with lung isolation, A 10-mm thoracoscopic port is inserted through the eighth or ninth intercostal space (ICS), and a $10-\mathrm{mm}$ 30-degree high-definition camera is inserted. One or 2 extra ports are inserted: usually a $10-\mathrm{mm}$ port in the fifth/sixth ICS in the anterior axillary line and a 5-mm port in the third/ fourth ICS in the anterior axillary line or a $10-\mathrm{mm}$ port in the fifth/sixth ICS below the scapula tip. Intraoperative fluoroscopy is conducted with a $\mathrm{C}$-arm device that approaches the patient from the posterior once in the lateral decubitus position. Fluoroscopy is conducted in short bursts with a foot pedal (Figure 1, B). By using forceps, the lung parenchyma is grasped and the microcoil is identified using short bursts of fluoroscopy (Video 1). The deep end of the coil is visualized with fluoroscopy, and the stapler is placed deep to the coil. After the stapler is closed and shown to be clear of the coil at fluoroscopy, the stapler is fired and the first cut is completed. After confirmation (each time with a short burst of fluoroscopy) that the coil is fully placed in the resected segment with proper oncological margins, the lesion is completely excised using multiple staplings. The resected wedge of lung tissue is withdrawn through the 10 -mm chest wall incision by using an endoscopic retrieval bag.

We perform an x-ray in the specimen to confirm the removal of the microcoil and assess the margins grossly (Figure 1, C). Finally, we proceed with lymph node sampling of mediastinal and hilar lymph nodes. Hemostasis is verified, a $28 \mathrm{~F}$ chest tube is inserted through the most dependent port site, and the lung is reexpanded.

\section{RESULTS}

\section{Participants}

A total of 97 lung nodules were resected with CT-guided microcoils in 92 subjects during the study period. All 97 lung nodules were included in the final analysis. 


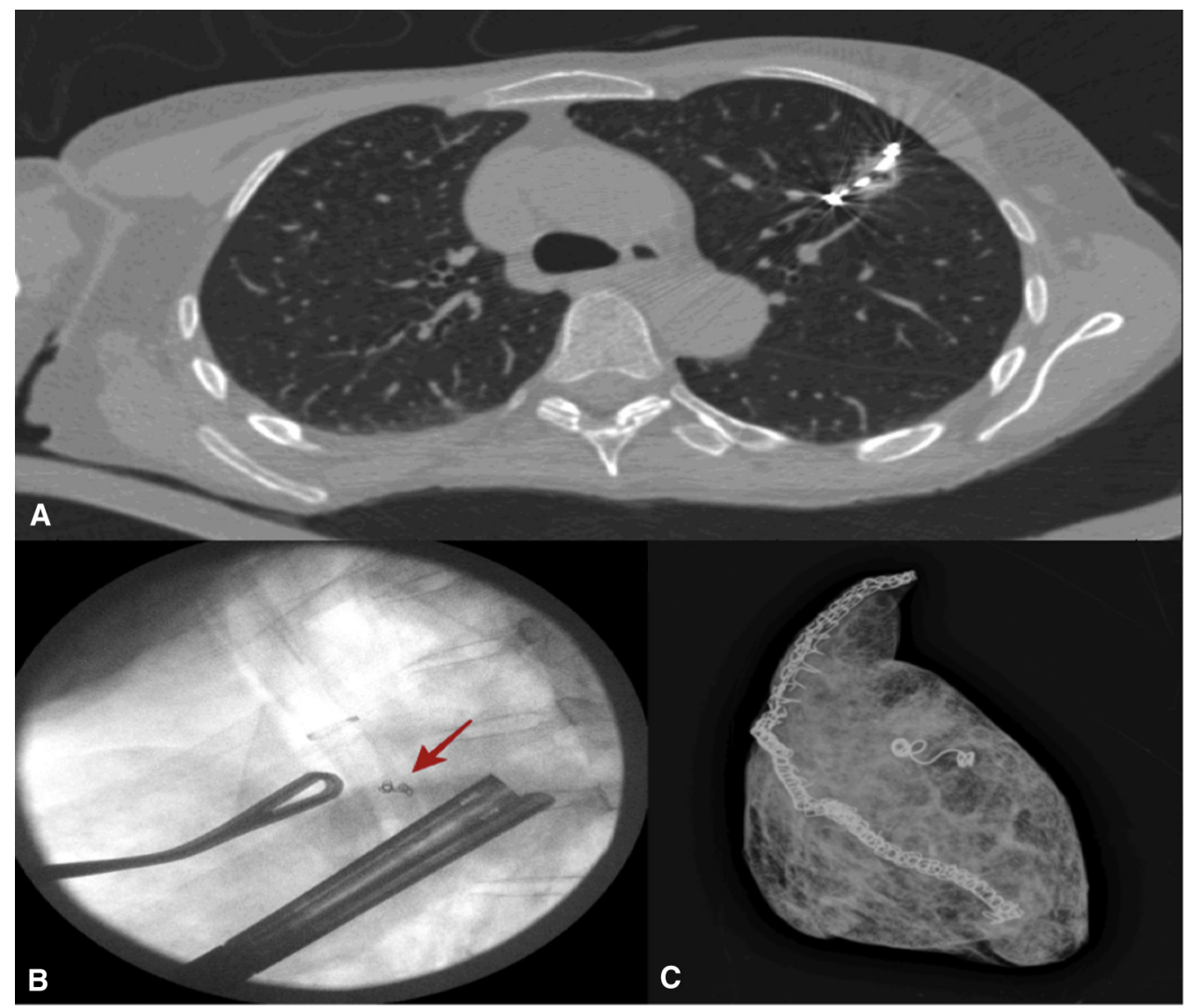

FIGURE 1. A, CT of the chest showing microcoil placed adjacent to a suspicious nodule. B, Intraoperative microcoil localization (arrow) with fluoroscopy. $\mathrm{C}$, Postresection specimen $\mathrm{x}$-ray showing successful removal of the microcoil marker.

\section{Descriptive Analysis}

Mean subject age was $65.3( \pm 10.6)$ years, 59 participants $(64.1 \%)$ were female, and $47 \%$ were former smokers. Additional demographic characteristics are summarized in Table 1. All 97 nodules (100\%) were successfully localized using video-assisted thoracic surgery wedge resection. There were 59 per microcoil $(60.8 \%)$ cases of placementrelated events noted on CT of the chest. All were minor and self-limited in nature, and did not require treatment: pneumothorax 45 (46.4\%), lung hematoma 18 (18.6\%), dislodgement into pleural space $4(4.1 \%)$, and hemoptysis $2(2.1 \%)$ (Table 2$)$. CT of the chest maximum mean nodule diameter was $13.2 \mathrm{~mm}( \pm 6.7)$. Nodule density was nonsolid in $27(27.8 \%)$, semi-solid in $27(27.8 \%)$, and purely solid in $43(44.3 \%)$. There was a single case of positive surgical margin, and $4(4.1 \%)$ went on to completion lobectomy for invasive NSCLC under a second anesthetic. NSCLC was identified in 66 nodules, with 8th Edition American Joint Committee on Cancer NSCLC staging as follows: pTis (20), pTmi (14), pT1a (13), pT1b (14), pT1c (3), and pT2a (2) (microscopic visceral pleura invasion). Of the invasive NSCLC, 26 were adenocarcinoma and 2 were squamous cell carcinoma. Metastatic neoplasms were identified in 13 nodules: colon adenocarcinoma 9 , thyroid carcinoma 2 , soft tissue sarcoma 1 , and metastatic melanoma 1. The remaining 14 nodules revealed benign histopathology: 5 granulomas, 5 postchemotherapy inflammatory fibrosis, 2 benign lymph nodes, 1 Cryptococcal fungus ball, and 1 Langerhans cell histiocytosis (Table 3 ). The mean radiation exposure was 6.3 (6.7) $\mathrm{mGy}$, with a fluoroscopy time of 50 (47.8) seconds. The mean (standard deviation) length of stay (LOS) postoperatively was 3.7 (2.1) days. There were no in hospital or 30-day mortalities. Additional operative characteristics are reported in Table 4.

\section{Univariable Analysis}

The relationship of nodule depth from visceral pleural edge and CT-guided microcoil placement-related adverse events is summarized in Tables 5 and 6 . On univariable analysis, pulmonary hematoma was the only microcoil placement-related adverse event strongly associated with nodule location $30 \mathrm{~mm}$ or greater from the visceral pleural 
TABLE 1. Computed tomography-guided microcoil placement study participant characteristics $(n=92)$

\begin{tabular}{lc}
\hline \multicolumn{1}{c}{ Variable } & \multicolumn{1}{c}{$\mathbf{n}(\%)$} \\
\hline Age-mean (SD), median (range) & $65.3(10.6)$ \\
Women & $59(64.1)$ \\
\hline $\begin{array}{l}\text { BMI }\left(\mathrm{kg} / \mathrm{m}^{2}\right) \text {-mean (SD); } \\
\quad \text { median (range) }\end{array}$ & $26.2(5.1) ; 25.5(17.8-44.4)$ \\
FEV $1 \%$-mean (SD); median (range) & $84.1(21) ; 89(31-117)$ \\
DLCO $\%$-mean (SD), median (range) & $80.8(17.9) ; 82(38-133)$ \\
Smoking status n (\%) & $11(11.22)$ \\
$\quad$ Current & $46(46.94)$ \\
$\quad$ Former & $41(41.84)$ \\
$\quad$ Never & $2.4(2.1) ; 2(0-9)$ \\
Charlson Comorbid Index-mean (SD); & \\
$\quad$ median (range) & $19(19.39)$ \\
\hline Previous lung resection &
\end{tabular}

$S D$, Standard deviation; $B M I$, body mass index; $F E V I \%$, forced expiratory volume in 1 second; $D L C O \%$, carbon monoxide lung diffusion capacity.

$(P=.005)$. A Charlson Comorbid Index of 4 or greater $(P=.006)$ and nodule depth $30 \mathrm{~mm}$ or greater (odds ratio, $3.45 ; 95 \%$ confidence interval, $1.13-10.51 ; P=.020$ ) were both strongly associated with a LOS 3 days or more (Table 7).

\section{DISCUSSION}

\section{Key Results and Interpretation}

CT-guided platinum microcoil lung surgery is safe with a favorable clinical adverse event profile, and as such may be suitable for poor-risk patients. We demonstrated that a significant proportion of our study population possess significant clinical comorbidity, with a Charlson Comorbid Index greater than 4 . In routine clinical practice, we demonstrate that the method is effective and efficient, yielding 100\% diagnostic localization in this 5-year update. It essentially eliminates need for thoracotomy and palpation to localize subpleural tiny nodules worrisome for malignancy. It is also ideal for management of changing nodules concerning for early lung cancer and for diagnosis of small indeterminate lung nodules or metastases.

This is the largest reported series of microcoil-guided pulmonary resection from a single center. Clinical implications of CT microcoil placement-related adverse

TABLE 2. Computed tomography-guided microcoil placement-related adverse events per coil $\mathbf{n}=59 / 97(60.8 \%)$

\begin{tabular}{lc}
\hline \multicolumn{1}{c}{ Variable } & $\mathbf{n}(\%)$ \\
\hline Microcoil dislodgement & $4(4.1)$ \\
Pneumothorax & $45(46.4)$ \\
Lung hematoma & $18(18.6)$ \\
Hemoptysis & $2(2.1)$ \\
\hline
\end{tabular}

TABLE 3. Computed tomography-guided microcoil placement nodule characteristics $(\mathbf{n}=97)$

\begin{tabular}{|c|c|}
\hline Variable & n $(\%)$ \\
\hline \multicolumn{2}{|l|}{ Preoperative chest $\mathrm{CT}$ nodule characteristics } \\
\hline \multicolumn{2}{|l|}{ Preoperative appearance on chest CT } \\
\hline Subsolid or ground glass & 27 (27.6) \\
\hline Semi-solid & $28(28.6)$ \\
\hline Solid & $43(43.9)$ \\
\hline \multicolumn{2}{|l|}{ Nodule location on chest CT } \\
\hline RUL & $37(38.1)$ \\
\hline RML & $1(1.0)$ \\
\hline RLL & $15(15.5)$ \\
\hline LUL & $28(28.9)$ \\
\hline LLL & $16(16.5)$ \\
\hline $\begin{array}{l}\text { Max diameter }(\mathrm{mm}) \text {-mean }(\mathrm{SD}) ; \\
\text { median (range) }\end{array}$ & $13.2(6.7) ; 12(4-40)$ \\
\hline $\begin{array}{l}\text { Max solid diameter (mm)-mean (SD); } \\
\text { median (range) }\end{array}$ & 7.7 (4.7); $8(0-18)$ \\
\hline $\begin{array}{l}\text { Nodule depth }(\mathrm{mm}) \text { from visceral } \\
\text { pleura-mean }(\mathrm{SD}) ; \text { median (range) }\end{array}$ & $27.0(9.1) ; 25.7(12.4-50.7)$ \\
\hline \multicolumn{2}{|l|}{ Surgical pathology nodule characteristics } \\
\hline Successful nodule excision & $97(100)$ \\
\hline Clear margin & $96(98.9)$ \\
\hline $\begin{array}{l}\text { Margin distance (mm)-mean (SD); } \\
\text { median (range) }\end{array}$ & $10.9(8.0) ; 10.0(1-32)$ \\
\hline \multicolumn{2}{|l|}{ Final diagnosis } \\
\hline \multicolumn{2}{|l|}{ Primary lung neoplasm } \\
\hline AAH & $3(3.09)$ \\
\hline AIS & $20(20.62)$ \\
\hline MIA & $18(18.56)$ \\
\hline Invasive $\mathrm{AC}$ & $26(26.80)$ \\
\hline SCC lung & $2(2.06)$ \\
\hline \multicolumn{2}{|l|}{ Secondary lung neoplasm } \\
\hline Metastatic colon cancer & $9(9.28)$ \\
\hline Metastatic thyroid cancer & $2(2.06)$ \\
\hline Metastatic soft tissue sarcoma & $1(1.03)$ \\
\hline Metastatic melanoma & $1(1.03)$ \\
\hline \multicolumn{2}{|l|}{ Non-neoplastic } \\
\hline Necrotizing granuloma & $3(3.09)$ \\
\hline Non-necrotizing granuloma & $2(2.06)$ \\
\hline $\begin{array}{l}\text { Postchemotherapy inflammatory } \\
\text { fibrosis }\end{array}$ & $2(2.06)$ \\
\hline Postinfection inflammatory fibrosis & $3(3.09)$ \\
\hline Infection-Cryptococcus & $1(1.03)$ \\
\hline Benign lymph node & $2(2.06)$ \\
\hline Langerhans cell histiocytosis & $1(1.03)$ \\
\hline pT Stage AJCC 8th Edition NSCLC & $\mathrm{n}=66$ \\
\hline pTis & $20(30.3)$ \\
\hline pTmi & $14(21.2)$ \\
\hline pT1a & 13 \\
\hline pT1b & 14 \\
\hline pT1c & 3 \\
\hline pT2a [visceral pleura] & 2 \\
\hline
\end{tabular}

$C T$, Computed tomography; $R U L$, right upper lobe; $R M L$, right middle lobe; $R L L$, right lower lobe; $L U L$, left upper lobe; $L L L$, left lower lobe; $S D$, standard deviation; $A A H$, atypical adenomatous hyperplasia; $A I S$, adenocarcinoma in situ; $M I A$, minimally invasive adenocarcinoma; $A C$, adenocarcinoma; SCC, squamous cell carcinoma; AJCC, American Joint Committee on Cancer; NSCLC, non-small cell lung cancer. 
TABLE 4. Operative and postoperative characteristics

\begin{tabular}{|c|c|}
\hline Variable & n $(\%)$ \\
\hline VATS incision & 97 (100) \\
\hline Wedge resection & $97(100)$ \\
\hline Successful microcoil localization & $97(100)$ \\
\hline $\begin{array}{l}\text { Radiation exposure (mGy)-mean (SD); } \\
\text { median (range) }\end{array}$ & $6.3(6.7) ; 4.7(3.9-46.1)$ \\
\hline $\begin{array}{l}\text { Duration fluoroscopy (s)-mean (SD); } \\
\text { median (range) }\end{array}$ & 50 (47.8); 37 (3-295) \\
\hline $\begin{array}{l}\text { Completion lobectomy for invasive } \\
\text { NSCLC under second GA }\end{array}$ & $4(4.1)^{*}$ \\
\hline LOS (d)-mean (SD); median (range) & $3.7(2.1) ; 3(1-12)$ \\
\hline $\operatorname{LOS}>3 \mathrm{~d}$ & $63(64.29)$ \\
\hline $\begin{array}{l}\text { Postoperative adverse events, } \mathrm{n}(\%) \\
\text { Mortality-30 d }\end{array}$ & $26(26.8)$ \\
\hline
\end{tabular}

events seen on chest CT immediately postplacement have not been reported with such detail previously. The rate of placement-related adverse events have increased overall in our cohort compared with previous reports. ${ }^{4}$ Of note, at our institution we have expanded our criteria for postmicrocoil placement of chest CT reporting what is considered an "event" (eg, tiny postprocedure pneumothorax or lung hematoma), while at the same time we have expanded our clinical indications for the use of microcoil. Our finding that all reported adverse events were minor and not clinically relevant for patients supports this change in local practice pattern. Likely given our increasing familiarity with the microcoil technique over a decade, we have expanded indications for CT-guided

TABLE 5. Analysis of any microcoil placement complication and patient characteristics

\begin{tabular}{|c|c|c|}
\hline Variable & $\begin{array}{c}\text { Univariable } \\
\text { analysis OR } \\
(95 \% \text { CI })\end{array}$ & $P$ value \\
\hline Sex & $1.17(0.51-2.69)$ & .711 \\
\hline$>1$ coil placement & $0.92(0.27-3.14)$ & .888 \\
\hline FEV1 $>50 \%$ & $0.86(0.22-3.39)$ & .826 \\
\hline DLCO $>50 \%$ & $1.25(0.24-6.65)$ & .789 \\
\hline $\mathrm{BMI}>25 \mathrm{~kg} / \mathrm{m}^{2}$ & $0.97(0.42-2.21)$ & .938 \\
\hline Current or former smoker & $0.79(0.35-1.82)$ & .584 \\
\hline $\mathrm{CCI} \geq 4$ & $2.41(0.84-6.92)$ & .090 \\
\hline Nodule $\geq 20 \mathrm{~mm}$ from visceral pleura & $1.39(0.54-3.55)$ & .489 \\
\hline Nodule $\geq 30 \mathrm{~mm}$ from visceral pleura & $1.98(0.76-5.19)$ & .153 \\
\hline
\end{tabular}

TABLE 6. Analysis of microcoil placement complications with nodules located greater or less than $30 \mathrm{~mm}$ from the visceral pleural surface

\begin{tabular}{llc}
\hline \multicolumn{1}{c}{ Variable } & $\begin{array}{c}\text { Univariable } \\
\text { analysis OR } \\
(\mathbf{9 5} \% \mathbf{C I})\end{array}$ & $\boldsymbol{P}$ value \\
\hline $\begin{array}{l}\text { Any microcoil placement-related } \\
\text { adverse event }\end{array}$ & $1.99(0.76-5.19)$ & .153 \\
Microcoil dislodgement & $0.83(0.08-8.41)$ & .872 \\
\hline Pneumothorax & $1.01(0.43-2.49)$ & .949 \\
Lung hematoma & $4.31(1.41-13.18)$ & .005 \\
\hline OR, Odds ratio; $C I$, confidence interval. & &
\end{tabular}

microcoil placement compared with previous series to include deeper nodules located $30 \mathrm{~mm}$ or greater from the pleural surface, patients with increased burden of comorbid disease, and multiple suspicious nodules in the same lung. Although not statistically significant in this series because of the small numbers of this subgroup (5 cases), placement of a second microcoil may increase the chance of an observable pneumothorax or hematoma on postprocedure chest CT, which we would then report routinely as a procedure-related event.

Our high diagnostic rate $(100 \%)$ is also consistent with modern reports for CT microcoil-guided lung surgery. ${ }^{21}$ We have found of utmost importance for a high diagnostic rate is collaborative discussion with radiologists as to optimal location for microcoil placement facilitating ease of resection. We routinely review imaging together before each case. The reported average LOS of just more than 3 days is approximately 1 day longer than that reported in the literature of 2.5 days from other similar high-volume tertiary thoracic surgical institutions, ${ }^{21}$ but similar to our previous institutional reports. ${ }^{3,4}$ These differences in LOS may reflect institutional bias with respect to postoperative care algorithms, especially with respect to timing and protocols for chest tube removal. Given the association in this study identified with greater LOS and Charlson

TABLE 7. Analysis of patient characteristics for association with length of stay 3 days or more

\begin{tabular}{llc}
\hline \multicolumn{1}{c}{ Variable } & $\begin{array}{c}\text { Univariable } \\
\text { analysis OR } \\
(\mathbf{9 5 \%} \mathbf{~ C I})\end{array}$ & $\boldsymbol{P}$ value \\
\hline $\mathrm{CCI} \geq 4$ & $5.33(1.38-20.64)$ & .006 \\
\hline Current or former smoker & $1.84(0.79-4.31)$ & .154 \\
\hline $\mathrm{BMI}>25 \mathrm{~kg} / \mathrm{m}^{2}$ & $1.29(0.56-2.99)$ & .552 \\
\hline Microcoil placement complication & $1.46(0.62-3.42)$ & .375 \\
\hline DLCO $>50 \%$ & $1.43(0.23-8.75)$ & .698 \\
\hline Nodule $\geq 20 \mathrm{~mm}$ from visceral pleura & $2.79(1.05-7.39)$ & .031 \\
\hline Nodule $\geq 30 \mathrm{~mm}$ from visceral pleura & $3.45(1.13-10.51)$ & .020 \\
\hline
\end{tabular}

$O R$, Odds ratio; $C I$, confidence interval; $C C I$, Charlson Comorbid Index; $B M I$, body mass index; $D L C O$, carbon monoxide lung diffusion capacity. 
Comorbid Index 4 or greater, it may be that our population selected for microcoil surgery has a different or higher comorbidity burden than in other thoracic centers. However, given that this study was conducted in the routine clinical practice setting, not in the context of a clinical trial, the findings are likely more generalizable than previous studies.

\section{Study Limitations}

There are several limitations to the current study. These arise primarily from the retrospective nature of the design and the potential for information bias affecting estimates. The prospectively collected thoracic surgical outcomes database attempts to minimize information bias with standardized reporting of postoperative adverse events. However, there was no such standardized database with respect to reporting of adverse events related to microcoil placement. In this case, event reporting was reliant on the radiologist preforming the procedure. This does pose the possibility that the proportion of all adverse events (minor and major) associated with CT-guided microcoil placement was underestimated if not all minor events were reported. If under-reported, this could result in differential misclassification of those who did have a minor complication, in particular related to microcoil placement. Misclassification of a nonexposed adverse event group would serve to decrease the observed proportion of this primary outcome measure.

\section{CONCLUSIONS}

CT-guided platinum microcoil lung surgery is safe with a favorable clinical adverse event profile and as such may be suitable for poor-risk patients. In routine clinical practice, we demonstrate this method is effective, yielding $100 \%$ diagnostic localization in this 5-year update.

\section{Conflict of Interest Statement}

Authors have nothing to disclose with regard to commercial support.

The authors thank P. Brasher, $\mathrm{PhD}$, for conducting a statistical review of our article.

\section{References}

1. National Lung Screening Trial Research Team, Aberle DR, Adams AM, et al Reduced lung-cancer mortality with low-dose computed tomographic screening. N Engl J Med. 2011;365:395-409.

2. McWilliams A, Tammemagi MC, Mayo JR, Roberts H, Liu G, Soghrati K, et al. Probability of cancer in pulmonary nodules detected on first screening CT. N Engl J Med. 2013;369:910.
3. Finley RJ, Mayo JR, Grant K, Clifton JC, English J, Leo J, et al. Preoperative computed tomography-guided microcoil localization of small peripheral pulmonary nodules: a prospective randomized controlled trial. J Thorac Cardiovasc Surg. 2015;149:26-31.

4. Mayo JR, Clifton JC, Powell TI, English JC, Evans KG, Yee J, et al. Lung nodules: CT-guided placement of microcoils to direct video-assisted thoracoscopic surgical resection. Radiology. 2009;250:576-85.

5. Bommart S, Bourdin A, Marin G, Berthet JP, Pujol JL, Serre I, et al. Impact of preoperative marking coils on surgical and pathologic management of impalpable lung nodules. Ann Thorac Surg. 2014;97:414-8.

6. Sui X, Zhao H, Yang F, Li JL, Wang J. Computed tomography guided microcoil localization for pulmonary small nodules and ground-glass opacity prior to thoracoscopic resection. J Thorac Dis. 2015;7:1580-7.

7. Su TH, Fan YF, Jin L, He W, Hu LB. CT-guided localization of small pulmonary nodules using adjacent microcoil implantation prior to video-assisted thoracoscopic surgical resection. Eur Radiol. 2015;25:2627-33.

8. Yamamoto M, Takeo M, Meguro F, Ishikawa T. Sonographic evaluation for peripheral pulmonary nodules during video-assisted thoracoscopic surgery. Surg Endosc. 2003;17:825-7.

9. Santambrogio R, Montorsi M, Bianchi P, Mantovani A, Ghelma F, Mezzetti M. Intraoperative ultrasound during thoracoscopic procedures for solitary pulmonary nodules. Ann Thorac Surg. 1999;68:218-22.

10. Gossot D, Miaux Y, Guermazi A, Celerier M, Friga J. The hook-wire technique for localization of pulmonary nodules during thoracoscopic resection. Chest. 1994;105:1467-9.

11. Ciriaco P, Negri G, Puglisi A, Nicoletti R, Del Maschio A, Zannini P. Video-assisted thoracoscopic surgery for pulmonary nodules: rationale for preoperative computed tomography-guided hookwire localization. Eur J Cardiothorac Surg. 2004;25:429-33.

12. Wicky S, Dusmet M, Doenz F, Ris HB, Schnyder P, Portier F. Computed tomography-guided localization of small lung nodules before video-assisted resection: experience with an efficient hook-wire system. J Thorac Cardiovasc Surg. 2002; 124:401-3.

13. Kanazawa S, Ando A, Yasui K, Tanaka A, Hiraki Y. Localization of small pulmonary nodules for thoracoscopic resection: use of a newly developed hookwire system. Cardiovasc Intervent Radiol. 1995;18:122-4.

14. Torre M, Ferraroli GM, Vanzulli A, Fieschi S. A new safe and stable spiral wire needle for thoracoscopic resection of lung nodules. Chest. 2004;125:2289-93.

15. Eichfeld U, Dietrich A, Ott R, Kloeppel R. Video-assisted thoracoscopic surgery for pulmonary nodules after computed tomography-guided marking with a spiral wire. Ann Thorac Surg. 2005;79:313-7.

16. Wang YZ, Boudreaux JP, Dowling A, Woltering EA. Percutaneous localisation of pulmonary nodules prior to video-assisted thoracoscopic surgery using methylene blue and TC-99. Eur J Cardiothorac Surg. 2010;37: 237-8.

17. Moon SW, Wang YP, Jo KH, Kwack MS, Kim SW, Kwon OK, et al. Fluoroscopyaided thoracoscopic resection of pulmonary nodule localized with contrast media. Ann Thorac Surg. 1999;68:1815-20.

18. Lenglinger FX, Schwarz CD, Artmann W. Localization of pulmonary nodules before thoracoscopic surgery: value of percutaneous staining with methylene blue. AJR Am J Roentgenol. 1994;163:297-300.

19. Willekes L, Boutros C, Goldfarb MA. VATS intraoperative tattooing to facilitate solitary pulmonary nodule resection. J Cardiothorac Surg. 2008;3:13.

20. Magistrelli P, D’Ambra L, Berti S, Feleppa C, Stefanini T, Falco E. Use of India ink during preoperative computed tomography localization of small peripheral undiagnosed pulmonary nodules for thoracoscopic resection. World J Surg. 2009;33:1421-4.

21. Donahoe LL, Nguyen ET, Chung T, Kha L, Cypel M, Darling GE, et al. CT-guided microcoil VATS resection of lung nodules: a single-centre experience and review of the literature. J Thorac Dis. 2016;8:1986-94.

Key Words: lung cancer, thoracic surgery, VATS, thoracoscopic surgery 